\title{
Myeloid neoplasms after chemotherapy and PRRT: myth and reality
}

\author{
Lisa Bodei1,2,*, Irvin M Modlin2,3, Markus Luster4,*, Flavio Forrer5,*, Marta Cremonesi6, \\ Rodney J Hicks7, Samer Ezziddin8,*, Mark Kidd ${ }^{9}$ and Arturo Chiti10,*
}

1Department of Radiology, Memorial Sloan Kettering Cancer Center, New York, New York, USA

2LuGenlum Consortium for Independent Research, Milan, Rotterdam, Bad Berka, London

${ }^{3}$ Emeritus Professor Gastroenterological Surgery, Yale University, School of Medicine, New Haven, Connecticut, USA

${ }^{4}$ Department of Nuclear Medicine, University Hospital Marburg, Marburg, Germany

${ }^{5}$ Nuclear Medicine, Cantonal Hospital, St. Gallen, Switzerland

${ }^{6}$ Division of Health Physics, European Institute of Oncology, Milan, Italy

${ }^{7}$ Centre for Cancer Imaging, The Peter MacCallum Cancer Centre, St Andrew's Place, East Melbourne, Australia

${ }^{8}$ Department of Nuclear Medicine, Saarland University Hospital, Homburg, Saarland, Germany

${ }^{9}$ Wren Laboratories, Branford, Connecticut, USA

${ }^{10}$ Humanitas University, Milan, Italy

*(on behalf of the EANM Radionuclide Therapy Committee and the EANM)

Correspondence should be addressed to L Bodei

Email

bodeil@mskcc.org

\begin{abstract}
Peptide receptor radionuclide therapy (PRRT) with ${ }^{90} \mathrm{Y}$-octreotide or ${ }^{177} \mathrm{Lu}$-octreotate is an effective treatment for inoperable or metastatic neuroendocrine tumors (NETs), particularly well-differentiated gastroenteropancreatic or bronchopulmonary NETs. PRRT is generally extremely well tolerated, with modest toxicity to target organs, kidney and bone marrow. Nevertheless, a priori concerns regarding long-term effects lead clinicians such as Brieau and coworkers, in this ERC issue, to ascribe to the combination of alkylating agents and PRRT the apparently high occurrence $(n=4)$ of myeloproliferative events (therapy-related myeloid neoplasms (t-MNs)) in a small cohort of 20 progressive, advanced digestive NETs treated with PRRT after chemotherapy. Anecdotal reports of myelotoxic events should be placed in the correct perspective of larger series, where the reported incidence of these events is $\sim 2 \%$, with the aim of promoting a balanced awareness of the issue and unbiased and reasonable overall conclusions. For a comprehensive definition of the issue, we provide an evaluation of the occurrence of t-MN in patients treated with various myelotoxic treatments.
\end{abstract}

\author{
Key Words \\ - myeloid neoplasms \\ - alkylating chemotherapy \\ - PRRT \\ - neuroendocrine tumors
}

\section{Introduction}

It is now widely accepted that peptide receptor radionuclide therapy (PRRT) is an effective treatment for inoperable or metastatic neuroendocrine tumors (NETs), particularly well-differentiated gastroenteropancreatic (GEP) or bronchopulmonary NETs. Twenty years of well-documented investigation in reputable institutions have yielded unequivocal evidence of efficacy with the commonly used radiopeptides, ${ }^{90}$ Y-octreotide and ${ }^{177} \mathrm{Lu}$-octreotate. The objective response rates range from 15 to $35 \%$ and the progression-free survival rates exceed 30 months. These results are recapitulated by the preliminary, as yet unpublished, randomized-controlled

Published by Bioscientifica Ltd 
trial (NETTER-1) (Strosberg et al. 2015). The projected overall survival rates in the latter compare favorably with conventional therapies including somatostatin analogs, chemotherapy, and recently approved therapies including everolimus and sunitinib. Cumulative experience has led to widespread clinical acceptance of ${ }^{177} \mathrm{Lu}$-octreotate as the radiopeptide of choice due to its favorable response rates and lower incidence of nephrotoxicity compared to ${ }^{90}$ Y-octreotide.

PRRT is generally extremely well tolerated, with modest toxicity to target organs, kidney and bone marrow. Serious adverse events are scarce and mostly unpredictable, because their pathogenesis is poorly understood and, in some cases, apparently idiosyncratic (Frilling et al. 2014).

\section{Main text}

Toxicity associated with PRRT is categorized as acute, subacute or long term. Acute and subacute side effects are typically mild and self-limiting, comprising fatigue (common), nausea (25\%, rarely vomiting), hair loss (maximum grade 1 60\%), abdominal pain (10\%) and occasionally hormonal crisis (1\%) (Kwekkeboom \& Krenning 2016). Nausea (controlled effectively by antiemetic therapies, e.g., granisetron) is related to concomitant administration of 'nephro-protective' amino acids (Bernard et al. 1997, Bodei et al. 2003). Other subacute side effects are radiation related (Kwekkeboom et al. 2005, van Essen et al. 2008, Kwekkeboom \& Krenning 2016). Hematologic toxicity, the most common subacute side effect, is typically mild (WHO grades $1-2$ ) and reverses within weeks of treatment cessation. More severe WHO grade 3 or 4 form (generally reversible within 2-3 months) occurs in $<15 \%$ patients, irrespective of the radiopeptide utilized. However, in $\sim 50 \%$ of these patients, it may persist (Kwekkeboom \& Krenning 2016). The mean recovery time was 12 months in a series of $203{ }^{177} \mathrm{Lu}$-octreotate-treated patients (Sabet et al. 2013). Neoplastic bone marrow involvement may increase the likelihood of myelotoxicity (Hubble et al. 2010). The majority of renal events are mild if the necessary precautions (such as nephroprotective amino acid coadministration and therapy adaptation to the clinical scenario) are undertaken (Bodei et al. 2009, Hofman \& Hicks 2014). In a cumulative analysis of nine individual series, 2500 patients/15years, chronic and permanent effects to target organs were infrequent with ${ }^{177} \mathrm{Lu}$-octreotate (Bodei et al. 2016). Loss of renal function grade 4 was $0.4 \%$, reduced bone marrow reserve and, more infrequently, myelodysplastic syndrome (MDS) was 2-2.3\% and leukemia (1.8\%), respectively (Bodei et al. 2016).
The concepts of PRRT tolerability (and potential negative outcomes) differ considerably between nuclear medicine physicians and referring oncologists, endocrinologists, and gastroenterologists. The former group accentuates the rarity of PRRT-related toxicity, whereas the latter, who are concerned a priori about 'therapy-induced' adverse events, believe them to be directly induced by internal radiation therapies. The putative rationale is that PRRT is responsible for all cases of nephropathy and the induction of mutagenic bone marrow events. The latter position is exemplified by the communication by Brieau and coworkers published in this issue (Brieau et al. 2016). This letter describes an apparently high incidence of myeloproliferative events in the long-term follow-up (3.1 years) of a small cohort of 20 progressive, advanced digestive NETs treated with PRRT after chemotherapy. Four patients (20\%) from a French oncology facility developed therapy-related myeloid neoplasms (t-MNs) 30-70 months after PRRT at the Erasmus Medical Center (EMC) Rotterdam. Compared to the rest of the cohort who also received PRRT, these 20 patients had more cycles of chemotherapy, more cycles of alkylating agents, experienced more frequent early high-grade hematotoxicity, and tended to more frequently have bone metastases. The authors infer that the very high occurrence of $\mathrm{t}-\mathrm{MN}$ in this cohort was due to previous administration of alkylating agents and therefore that these agents should be avoided before PRRT, particularly in the management of low-grade NETs. Their conclusion was that the combination of alkylating agents and PRRT poses a high risk of MDS. It should be noted that the precise causal relationship between t-MN and PRRT remains elusive. Only a small percentage ( 2\%) of patients after ${ }^{177} \mathrm{Lu}$-octreotate develop t-MN at the EMC (Kwekkeboom \& Krenning 2016).

Although the association with collateral myelotoxic therapy, including chemotherapy or radiotherapy, has previously been suggested, mathematical analysis of a series of more than 800 patients has led to reconsideration of the association. (Bodei et al. 2015). Although any added information that amplifies the understanding of t-MN after myelotoxic therapies is valuable, we are of the opinion that the interpretation of the results reported in this useful communication appears alarmist and unduly skeptical. Our major concern is the focus on this subset of very advanced and heavily pretreated patients referred to another center to receive salvage PRRT. They neither represent a prospectively enrolled cohort treated with PRRT after chemotherapy nor do they accurately reflect the average patient. The letter

Published by Bioscientifica Ltd. 
regrettably depicts anecdotal events defined in a selected subset, thereby providing a degree of bias that has led to an unreasonable overall conclusion. As currently presented, this engenders an erroneous assertion to a physician unfamiliar with the complexities of the subject that PRRT, used in a multidisciplinary fashion together or after chemotherapy (a registered treatment), has a significant risk (20\%) of causing MDS/AML. As noted, the pessimistic conclusions are reached in a small subset of over 700 patients treated with ${ }^{177} \mathrm{Lu}$-octreotate at the EMC Rotterdam (Kwekkeboom et al. 2008). In this group, the estimated incidence of these events is $\sim 2 \%$ (Kwekkeboom \& Krenning 2016). Of additional concern is the argument that the occurrence of t-MN in the GEP-NET population treated with alkylatingbased chemotherapy is only $1 \%$ (i.e., 1 of 95). This is misleading because patients are neither numerically matched nor matched for individual chemotherapy, years of follow-up, skeletal involvement, and so on. The presented analysis of a small subgroup of heavily pretreated and progressive patients referred to another center to receive salvage PRRT unfortunately reflects the current practice of utilizing PRRT in very advanced stages of disease. Such data cannot be utilized to signal a spurious negative alert regarding safety. In order to better define the issue and render it balanced, we have evaluated the occurrence of t-MN in patients treated with various myelotoxic treatments.

Myeloid neoplasms are considered either the consequence of mutational events induced by cytotoxic therapies or to arise via the selection of a myeloid clone with a mutator phenotype that has a markedly elevated risk for mutational events (Boehrer et al. 2009). MDS and AML secondary to chemo- or radiotherapy are a recognized category in the WHO 2008 classification (t-MN), as a nosologic group with a heterogeneous clinical outcome (Vardiman et al. 2009). The latency between diagnosis and therapy-related disease ranges from a few months to more than 10years, depending on the cumulative dosage or dose intensity of therapy and exposure to specific agents (Godley \& Larson 2008). The incidence of primary MDS is estimated at 3-20/100,000 and tends to increase with age (Rollison et al. 2008). No rigorous data that define the incidence of $\mathrm{t}-\mathrm{MN}$ are available; estimates indicate a range of $10-15 \%$ of all MDSs. The overall risk of t-MDS is therefore low but not negligible. In the assessment of clinical trials of alkylating therapy, an incidence of $0.25-1 \%$ per year beginning 2 years after the initiation of therapy and decreasing 7 years after the completion has been reported (Churpek \& Larson 2013).
The incidence of t-MN after chemotherapy trials exhibits large variations due to inherent selection biases, with the highest percentages reported with older forms of intensive treatments and smaller series (Churpek \& Larson 2013, Candelaria \& Duenas-Gonzalez 2015). Large series with extended follow-up are more reliable. In the SEER database (1975-2008), the occurrence of t-AML in more than 400,000 cancer patients treated with chemotherapy \pm radiotherapy was $0.18 \%$. This is 4 times higher than the normal population. Of note, radiochemotherapy combinations for solid cancers did not carry a significantly increased risk, compared with chemotherapy alone (Morton et al. 2013). Many conditions treated with alkylating agents have poor longterm survival, unlike that of low-grade NET, and therefore, estimates of the long-term impact of these agents on the development of t-MN may be underestimated.

t-MN secondary to radiation is more complex and is a multifactorial process that originates due to singleor double-strand breaks in the DNA, involving errors in repair mechanisms and genetic mutations, with loss of function or oncogene activation. A critical parameter is the different sensitivities of DNA to radiation during the cell cycle and intrinsic host repair mechanisms (Bourguignon et al. 2005). High-dose total body irradiation, as in atomic bomb survivors, Chernobyl nuclear disaster liquidators, or large-field conditioning radiotherapy before bone marrow transplantation, is known to be leukemogenic in a dose-dependent manner (Gluzman et al. 2015). However, the absolute rate of MDS is very low. A cohort study of Nagasaki A-bomb survivors identified only 198 cases out of 86,271 (0.2\%) irradiated individuals followed for 40-60years, with greatest risk among the young (Iwanaga et al. 2011). Although a potential increased risk of radiation therapy in association with chemotherapy has been reported (Sun et al. 2015), the relative contribution of chemotherapy to the incidence of t-MN is unclear. Follow-up of patients treated with chemotherapy for advanced Hodgkin lymphoma found t-MN in up to $2.7 \%$ (Engert et al. 2012). The mutagenic potential of lower doses of radiotherapy as used in modern radiation therapy planning, which greatly reduces the exposure of the bone marrow, is more controversial. This is especially relevant because many of the reported myeloid neoplasms share genetic features with de novo forms (Nardi et al. 2012, Cogle 2014, Zhang \& Wang 2014). In such cases, the correlation with irradiation is debatable and is considered representative of epiphenomena that are either coincidental or reflect individual genetic susceptibilities (Zhang \& Wang 2014).

Published by Bioscientifica Ltd. 
The same assertions may be made for radionuclide therapies, which are targeted therapies aimed at maximizing the target-to-normal tissue dose ratio, and exhibit a relatively limited total body distribution. One day after PRRT administration, radioactivity is typically $<1 \%$ in the blood and $<20 \%$ in the whole body, leading to cumulative red marrow and total body doses of $\sim 1$ and $\sim 1.5 \mathrm{~Gy}$, respectively (Cremonesi et al. 2010). t-MN after radionuclide therapies is considered uncommon and has only been sporadically reported with the various treatment modalities (radioiodine (RAI), ${ }^{131}$ I-metaiodobenzylguanidine (131-MIBG) (Matthay et al. 2007)), radioimmunotherapies (131 I or ${ }^{90} \mathrm{Y}$ ) (Leahy et al. 2006), and PRRT ( ${ }^{111} \mathrm{In},{ }^{90} \mathrm{Y}$, and $\left.{ }^{177} \mathrm{Lu}\right)$. As a consequence, studies are retrospective and statistical analyses include myeloproliferative events after radionuclide therapies generically encompassing the rubric of radiation therapy. Rigorous assessments are therefore not feasible.

Several studies combining the data of thyroid cancer patients of various age groups have shown that ${ }^{131} \mathrm{I}$ therapy may be associated with an increased risk for second primary malignancies (SPMs) (Rubino et al. 2003, Dottorini \& Salvatori 2013). However, dose-response relationships between radioiodine therapy and the risk of SPM were found in only a few studies (Clement et al. 2015). Brown and coworkers reviewed 30,000 SEER patients and identified a significant increase in second malignancies among patients treated with ${ }^{131}$ I (relative risk 1.16, $P<0.05$ ) (Brown et al. 2008), especially in younger patients. Another analysis of the SEER database $(n=27,775$ thyroid cancer patients surviving at least 5 years after diagnosis; 39\% treated with RAI) reported a relative risk attributable to radioiodine of 1.12 (95\% confidence interval (CI) 1.01-1.25) (Berrington de Gonzalez et al. 2011). A meta-analysis of RAI literature $(n=16,502)$ revealed a 2.5 -fold risk increase of leukemia (Grudeva-Popova et al. 2007). A separate systematic review of European and North America cohorts identified a $10-20 \%$ increase in secondary malignancies and that each GBq of ${ }^{131}$ I increased the risk of a second solid cancer by an average of 3.5\% and of leukemia by 39\% (Sawka et al. 2004). Whether this increase resulted from aggressive treatment or an underlying predisposition to cancer remains unclear because cause-effect relationships are difficult to establish. It is possible that these figures also reflect the longer life expectancy of thyroid cancer. In the Dusseldorf MDS Registry, t-MN following radioiodine therapy was $5 \%$ (8 of 173), with a median latency of 79 months. The karyotype was abnormal in $68 \%$, with aberrations noted most frequently in chromosomes 7, 5, 8, and 3 and a poor survival similar to those of patients with t-MN following other cytotoxic treatments (Schroeder et al. 2012a). In a separate cohort from Marseille $(n=10)$, $60 \%$ of the AL karyotypes had unfavorable characteristics. This suggests that four patients had de novo features, with an as yet undefined relationship to cytotoxic events (Gilabert \& Prebet 2012).

The non-Hodgkin lymphoma group of neoplasia is at considerable risk of developing secondary bone marrow neoplasms due to extensive myelotoxic treatments. The incidence of t-MDS was 2.5\% (19 patients of 746 NHL treated with ${ }^{90}$ Y-ibritumomab tiuxetan), occurring at a median interval of 5.6years from the primary chemotherapy and 1.9 years after radioimmunotherapy. The underlying cytogenetic aberrations, the time from the exposure, and the expected number of t-MNs were consistent with the previous exposure to chemotherapy, and the expected incidence was not increased by the radioimmunotherapy. The authors suggested that cytogenetic testing in heavily pretreated patients might identify those more likely to develop t-MN (Czuczman et al. 2007).

In comparison to other therapies, PRRT constitutes a relatively recent intervention. $t-M N$ events have been sporadically reported after ${ }^{111}$ In-pentetreotide, ${ }^{90}$ Y-octreotide and ${ }^{177} \mathrm{Lu}$-octreotate (Kwekkeboom et al. 2010). A recent analysis of the largest cohort available ( $n=807$ treated with ${ }^{90} \mathrm{Y}$ - and/or ${ }^{177} \mathrm{Lu}$-peptides) identified an incidence of $2.34 \%$ for MDS and $1.8 \%$ for leukemia (75\% evolved from MDS) (Bodei et al. 2015). The median latency from exposure was 4.4 years (Bodei et al. 2015). These data as well as those from the work of Brieau and coworkers suggest that the development of marrow neoplasms most likely is a consequence of previous treatments, such as chemotherapy. The percentage of cases with anomalous karyotypes after PRRT is, unfortunately, not known.

Given the demonstrable issue of secondary myeloid neoplasms, the need to predict or accurately assess the risk of such events is crucial. A clear dose-effect relationship, evident and linear with the dose for irradiation such as nuclear blasts (Gluzman et al. 2015), is not apparent in radionuclide therapies such as PRRT. In the latter, the doses delivered to the bone marrow are generally low (mean $0.02-0.07 \mathrm{~Gy} / \mathrm{GBq}$ ), resulting in a mean dose, for typical administrations of $7.4 \mathrm{GBq}$, of $0.15-0.5 \mathrm{~Gy}$. This is well below the threshold of $3.7 \mathrm{~Gy}$ for a single administration, as reported for radioiodine (Garkavij et al. 2010, Lassmann et al. 2010, Sandstrom et al. 2013). Despite the theoretical appeal correlating individual bone marrow

Published by Bioscientifica Ltd. 
doses with adverse effects, dosimetry has failed to provide a reliable instrument to predict myeloproliferative events in PRRT. A key issue is the difficulty in accurate bone marrow modeling (Cremonesi et al. 2010). In a cohort of 34 dosimetry-assessed patients, Bodei and coworkers, failed to demonstrate a clear correlation between dose and occurrence of t-MN. Furthermore, neither the amount of administered radioactivity nor the type of radionuclide employed had a significant impact on the occurrence of marrow neoplasms. This, together with the observation that only $29 \%$ of MDS and $22 \%$ of leukemia could be mathematically modeled by clinical data, suggests that intrinsic, genetically determined factors may have a critical role in the pathobiology of t-MNs (Bodei et al. 2015). This is substantiated by observations in radioiodine therapy for thyroid diseases where no difference could be established in the incidence of myeloid neoplasia between high activities used for cancer and low activities for benign diseases (Schroeder et al. 2012b). Such observations support the hypothesis of a preexisting biological (genomic) susceptibility to a radiation-induced effect.

In a post hoc analysis of t-MN etiopathology, it remains scientifically challenging to identify particular perpetrators. It is therefore important to resist the simplistic temptation to explain all events on 'known knowledge'. Although it is generally accepted as a fait accompli that a myelotoxic event is linked to myelotoxic therapies (cytotoxics or radiation), other explanations require consideration. It remains essential to rigorously identify and define stochastic events, susceptibility to mutagenic events, and myeloid neoplasia predisposition, irrespective of exposure (Churpek \& Larson 2013, Bueso-Ramos et al. 2015). It is noteworthy that many authors have proposed a role of individual genetic predisposition (Kitamura et al. 2014). The likelihood of an intrinsic molecular genomic basis is further supported by the increased incidence of myeloid neoplasia in Fanconi anemia, Li-Fraumeni syndrome, neurofibromatosis type 1, Down syndrome, as well as in circumstances characterized by genetic polymorphisms of enzymes involved in the metabolism of cytotoxic agents (e.g., glutathione $S$-transferase) (Liew \& Owen 2011, Churpek \& Larson 2013).

We agree that, in the absence of an accurate, personalized assessment of the individual risk of developing radiation associated disease, the use of radionuclide therapies in patients heavily pretreated with alkylating agents remains a cause for concern.
The possibility of developing a t-MN can never be ignored. However, anecdotal reports of myelotoxic events should be placed in the correct perspective of larger series, with the aim of promoting a balanced awareness of the issue rather than an emotional response that diminishes the utility and efficacy of the therapy. An incidence of an adverse event of $2-3 \%$ is worthy of clinical evaluation using a thoughtful risk-benefit ratio assessment (Strosberg et al. 2015) rather than succumbing to any unduly pessimistic assessment.

To move toward a more modern and personalized assessment of risk, in future evaluation of therapy, individual radiosensitivity will need to be assessed by specific biomarkers, such as chromosomal screening of bone marrow of patients potentially at risk, $\gamma$-H2AX assays (Denoyer et al. 2015), and genetic testing. An unmet need is the availability of pre- or intratherapeutic assessment of circulating transcriptional markers to predetermine or delineate impending neoplastic marrow events. The latter require identification and development for application to PRRT and other radiopharmaceutical therapies. The necessity for national registries as well as multidisciplinary assessments with mathematical integration of clinical, dosimetric, biomarker and genetic information is clearly needed. This will enable the development of objective risk assessment nomograms and facilitate risk-benefit quantification based upon impartial analysis of results obtained in long-term follow-up of large cohorts of comparable patients. Nevertheless, based on the data presented in the letter as well as our own experience with PRRT, we believe that the treatment of patients with low-grade tumors with alkylating chemotherapy should be avoided, and preference should be given to PRRT due to its the relatively high response rate, prolonged associated survival and low toxicity. More importantly, patients should avoid treatments associated with long-term toxicity unless there are uncontrolled symptoms or objective evidence of disease progression that, if unchecked, would lead to reduction in quality and duration of life.

\section{Declaration of interest}

The authors declare that there is no conflict of interest that could be perceived as prejudicing the impartiality of this commentary.

\section{Funding}

This work did not receive any specific grant from any funding agency in the public, commercial, or not-for-profit sector.
(C) 2016 Society for Endocrinology Printed in Great Britain
Published by Bioscientifica Ltd 


\section{References}

Bernard BF, Krenning EP, Breeman WA, Rolleman EJ, Bakker WH, Visser TJ, Macke H \& de Jong M 1997 D-lysine reduction of indium-111 octreotide and yttrium-90 octreotide renal uptake. Journal of Nuclear Medicine 38 1929-1933.

Berrington de Gonzalez A, Curtis RE, Kry SF, Gilbert E, Lamart S, Berg CD, Stovall M \& Ron E 2011 Proportion of second cancers attributable to radiotherapy treatment in adults: a cohort study in the US SEER cancer registries. Lancet Oncology 12 353-360. (doi:10.1016/S1470-2045(11)70061-4)

Bodei L, Cremonesi M, Zoboli S, Grana C, Bartolomei M, Rocca P, Caracciolo M, Macke HR, Chinol M \& Paganelli G 2003 Receptormediated radionuclide therapy with 90Y-DOTATOC in association with amino acid infusion: a phase I study. European Journal of Nuclear Medicine and Molecular Imaging 30 207-216. (doi:10.1007/s00259002-1023-y)

Bodei L, Ferone D, Grana CM, Cremonesi M, Signore A, Dierckx RA \& Paganelli G 2009 Peptide receptor therapies in neuroendocrine tumors. Journal of Endocrinological Investigation 32 360-369. (doi:10.1007/BF03345728)

Bodei L, Kidd M, Paganelli G, Grana CM, Drozdov I, Cremonesi M, Lepensky C, Kwekkeboom DJ, Baum RP, Krenning EP, et al. 2015 Long-term tolerability of PRRT in 807 patients with neuroendocrine tumours: the value and limitations of clinical factors. European Journal of Nuclear Medicine and Molecular Imaging 42 5-19. (doi:10.1007/s00259-014-2893-5)

Bodei L, Kwekkeboom DJ, Kidd M, Modlin IM \& Krenning EP 2016 Radiolabeled somatostatin analogue therapy of gastroenteropancreatic cancer. Seminars in Nuclear Medicine 46 225-238. (doi:10.1053/j.semnuclmed.2015.12.003)

Boehrer S, Adès L, Tajeddine N, Hofmann WK, Kriener S, Bug G, Ottmann OG, Ruthardt M, Galluzzi L, Fouassier C, et al. 2009 Suppression of the DNA damage response in acute myeloid leukemia versus myelodysplastic syndrome. Oncogene 28 2205-2218. (doi:10.1038/onc.2009.69)

Bourguignon MH, Gisone PA, Perez MR, Michelin S, Dubner D, Giorgio MD \& Carosella ED 2005 Genetic and epigenetic features in radiation sensitivity Part I: cell signalling in radiation response. European Journal of Nuclear Medicine and Molecular Imaging 32 229-246. (doi:10.1007/s00259-004-1731-6)

Brieau B, Hentic O, Lebtahi R, Palazzo M, Ben Reguiga M, Rebours V, Maire F, Hammel P, Ruszniewski P \& Fenaux P 2016 High occurrence of myelodysplasia after chemotherapy and $177 \mathrm{Lu}$ octreotate PRRT. Endocrine-Related Cancer 23 L17-L23. (doi:10.1530/ erc-15-0543)

Brown AP, Chen J, Hitchcock YJ, Szabo A, Shrieve DC \& Tward JD 2008 The risk of second primary malignancies up to three decades after the treatment of differentiated thyroid cancer. Journal of Clinical Endocrinology and Metabolism 93 504-515. (doi:10.1210/jc.2007-1154)

Bueso-Ramos CE, Kanagal-Shamanna R, Routbort MJ \& Hanson CA 2015 Therapy-related myeloid neoplasms. American Journal of Clinical Pathology 144 207-218. (doi:10.1309/AJCPU1JO2LYTWUAV)

Candelaria M \& Duenas-Gonzalez A 2015 Therapy-related myelodysplastic syndrome. Expert Opinion on Drug Safety 14 655-665. (doi:10.1517/14740338.2015.1014340)

Churpek JE \& Larson RA 2013 The evolving challenge of therapy-related myeloid neoplasms. Best Practice \& Research Clinical Haematology 26 309-317. (doi:10.1016/j.beha.2013.09.001)

Clement SC, Peeters RP, Ronckers CM, Links TP, van den HeuvelEibrink MM, Nieveen van Dijkum EJ, van Rijn RR, van der Pal HJ, Neggers SJ, Kremer LC, et al. 2015 Intermediate and long-term adverse effects of radioiodine therapy for differentiated thyroid carcinoma - a systematic review. Cancer Treatment Reviews $\mathbf{4 1}$ 925-934. (doi:10.1016/j.ctrv.2015.09.001)
Cogle CR 2014 Radiation alone for solid tumors and the questionable development of therapy-related myelodysplastic syndromes. Journal of the National Cancer Institute 106 dju025. (doi:10.1093/jnci/dju025)

Cremonesi M, Botta F, Di Dia A, Ferrari M, Bodei L, De Cicco C, Rossi A, Bartolomei M, Mei R, Severi S, et al. 2010 Dosimetry for treatment with radiolabelled somatostatin analogues. A review. Quarterly Journal of Nuclear Medicine and Molecular Imaging 54 37-51.

Czuczman MS, Emmanouilides C, Darif M, Witzig TE, Gordon LI, Revell S, Vo K \& Molina A 2007 Treatment-related myelodysplastic syndrome and acute myelogenous leukemia in patients treated with ibritumomab tiuxetan radioimmunotherapy. Journal of Clinical Oncology 25 4285-4292. (doi:10.1200/JCO.2006.09.2882)

Denoyer D, Lobachevsky P, Jackson P, Thompson M, Martin OA \& Hicks RJ 2015 Analysis of 177Lu-DOTA-octreotate therapy-induced DNA damage in peripheral blood lymphocytes of patients with neuroendocrine tumors. Journal of Nuclear Medicine 56 505-511. (doi:10.2967/jnumed.114.145581)

Dottorini ME \& Salvatori M 2013 Is radioiodine treatment for thyroid cancer a risk factor for second primary malignancies? Clinical and Translational Imaging 1 205-216.

Engert A, Haverkamp H, Kobe C, Markova J, Renner C, Ho A, Zijlstra J, Kral Z, Fuchs M, Hallek M, et al. 2012 Reduced-intensity chemotherapy and PET-guided radiotherapy in patients with advanced stage Hodgkin's lymphoma (HD15 trial): a randomised, open-label, phase 3 non-inferiority trial. Lancet 379 1791-1799. (doi:10.1016/S0140-6736(11)61940-5)

Frilling A, Modlin I, Kidd M, Russell C, Breitenstein S, Salem R, Kwekkeboom D, Lau W-Y, Klersy C, Vilgrain V, et al. 2014 Recommendations for management of patients with neuroendocrine liver metastases. Lancet Oncology 15 e8-e21. (doi:10.1016/s1470-2045(13)70362-0)

Garkavij M, Nickel M, Sjogreen-Gleisner K, Ljungberg M, Ohlsson T, Wingardh K, Strand SE \& Tennvall J 2010 177Lu-[DOTA0,Tyr3] octreotate therapy in patients with disseminated neuroendocrine tumors: analysis of dosimetry with impact on future therapeutic strategy. Cancer 116 1084-1092. (doi:10.1002/cncr.24796)

Gilabert M \& Prebet T 2012 Acute leukemia arising after radioiodine treatment for thyroid cancer. Haematologica 97 e28-e29. (doi:10.3324/haematol.2012.067454)

Gluzman DF, Sklyarenko LM, Koval SV, Rodionova NK, Zavelevich MP, Ivanivskaya TS, Poludnenko LY \& Ukrainskaya NI 2015 Myelodysplastic syndromes in Chernobyl clean-up workers. Annals of Hematology 94 1639-1643. (doi:10.1007/s00277-015-2441-9)

Godley LA \& Larson RA 2008 Therapy-related myeloid leukemia. Seminars in Oncology 35 418-429. (doi:10.1053/j. seminoncol.2008.04.012)

Grudeva-Popova J, Yaneva M, Zisov K \& Ananoshtev N 2007 Therapyrelated acute promyelocytic leukemia after treatment with radioiodine for thyroid cancer: case report with literature review. Journal of BUON 12 129-132.

Hofman MS \& Hicks RJ 2014 Peptide receptor radionuclide therapy for neuroendocrine tumours: standardized and randomized, or personalized? European Journal of Nuclear Medicine and Molecular Imaging 41 211-213. (doi:10.1007/s00259-013-2621-6)

Hubble D, Kong G, Michael M, Johnson V, Ramdave S \& Hicks RJ 2010 177Lu-octreotate, alone or with radiosensitising chemotherapy, is safe in neuroendocrine tumour patients previously treated with highactivity 111In-octreotide. European Journal of Nuclear Medicine and Molecular Imaging 37 1869-1875. (doi:10.1007/s00259-010-1483-4)

Iwanaga M, Hsu WL, Soda M, Takasaki Y, Tawara M, Joh T, Amenomori T, Yamamura M, Yoshida Y, Koba T, et al. 2011 Risk of myelodysplastic syndromes in people exposed to ionizing radiation: a retrospective cohort study of Nagasaki atomic bomb survivors. Journal of Clinical Oncology 29 428-434. (doi:10.1200/ JCO.2010.31.3080) http://erc.endocrinology-journals.org

DOI: 10.1530/ERC-16-0258
(C) 2016 Society for Endocrinology Printed in Great Britain
Published by Bioscientifica Ltd 
Kitamura T, Inoue D, Okochi-Watanabe N, Kato N, Komeno Y, Lu Y, Enomoto Y, Doki N, Uchida T, Kagiyama Y, et al. 2014 The molecular basis of myeloid malignancies. Proceedings of the Japan Academy. Series B, Physical and Biological Sciences 90 389-404.

Kwekkeboom DJ, de Herder WW, Kam BL, van Eijck CH, van Essen M, Kooij PP, Feelders RA, van Aken MO \& Krenning EP 2008 Treatment with the radiolabeled somatostatin analog [177 Lu-DOTA 0,Tyr3] octreotate: toxicity, efficacy, and survival. Journal of Clinical Oncology 26 2124-2130. (doi:10.1200/JCO.2007.15.2553)

Kwekkeboom DJ, Kam BL, van Essen M, Teunissen JJ, van Eijck CH, Valkema R, de Jong M, de Herder WW \& Krenning EP 2010 Somatostatin-receptor-based imaging and therapy of gastroenteropancreatic neuroendocrine tumors. Endocrine-Related Cancer 17 R53-R73. (doi:10.1677/erc-09-0078)

Kwekkeboom DJ \& Krenning EP 2016 Peptide receptor radionuclide therapy in the treatment of neuroendocrine tumors. Hematology/ Oncology Clinics of North America 30 179-191. (doi:10.1016/j. hoc.2015.09.009)

Kwekkeboom DJ, Teunissen JJ, Bakker WH, Kooij PP, de Herder WW, Feelders RA, van Eijck CH, Esser JP, Kam BL \& Krenning EP 2005 Radiolabeled somatostatin analog [177Lu-DOTA0,Tyr3]octreotate in patients with endocrine gastroenteropancreatic tumors. Journal of Clinical Oncology 23 2754-2762. (doi:10.1200/jco.2005.08.066)

Lassmann M, Reiners C \& Luster M 2010 Dosimetry and thyroid cancer: the individual dosage of radioiodine. Endocrine-Related Cancer $\mathbf{1 7}$ R161-R172. (doi:10.1677/erc-10-0071)

Leahy MF, Seymour JF, Hicks RJ \& Turner JH 2006 Multicenter phase II clinical study of iodine-131-rituximab radioimmunotherapy in relapsed or refractory indolent non-Hodgkin's lymphoma. Journal of Clinical Oncology 24 4418-4425. (doi:10.1200/JCO.2005.05.3470)

Liew E \& Owen C 2011 Familial myelodysplastic syndromes: a review of the literature. Haematologica 96 1536-1542. (doi:10.3324/ haematol.2011.043422)

Matthay KK, Yanik G, Messina J, Quach A, Huberty J, Cheng SC, Veatch J, Goldsby R, Brophy P, Kersun LS, et al. 2007 Phase II study on the effect of disease sites, age, and prior therapy on response to iodine-131-metaiodobenzylguanidine therapy in refractory neuroblastoma. Journal of Clinical Oncology 25 1054-1060. (doi:10.1200/jco.2006.09.3484)

Morton LM, Dores GM, Tucker MA, Kim CJ, Onel K, Gilbert ES, Fraumeni JF Jr \& Curtis RE 2013 Evolving risk of therapy-related acute myeloid leukemia following cancer chemotherapy among adults in the United States, 1975-2008. Blood 121 2996-3004. (doi:10.1182/blood-2012-08-448068)

Nardi V, Winkfield KM, Ok CY, Niemierko A, Kluk MJ, Attar EC, Garcia-Manero G, Wang SA \& Hasserjian RP 2012 Acute myeloid leukemia and myelodysplastic syndromes after radiation therapy are similar to de novo disease and differ from other therapyrelated myeloid neoplasms. Journal of Clinical Oncology 30 2340-2347. (doi:10.1200/JCO.2011.38.7340)

Rollison DE, Howlader N, Smith MT, Strom SS, Merritt WD, Ries LA, Edwards BK \& List AF 2008 Epidemiology of myelodysplastic syndromes and chronic myeloproliferative disorders in the United
States, 2001-2004, using data from the NAACCR and SEER programs. Blood 112 45-52. (doi:10.1182/blood-2008-01-134858)

Rubino C, de Vathaire F, Dottorini ME, Hall P, Schvartz C, Couette JE, Dondon MG, Abbas MT, Langlois C \& Schlumberger M 2003 Second primary malignancies in thyroid cancer patients. British Journal of Cancer 89 1638-1644. (doi:10.1038/sj.bjc.6601319)

Sabet A, Ezziddin K, Pape UF, Ahmadzadehfar H, Mayer K, Poppel T, Guhlke S, Biersack HJ \& Ezziddin S 2013 Long-term hematotoxicity after peptide receptor radionuclide therapy with $177 \mathrm{Lu}$-octreotate. Journal of Nuclear Medicine 54 1857-1861. (doi:10.2967/ jnumed.112.119347)

Sandstrom M, Garske-Roman U, Granberg D, Johansson S, Widstrom C, Eriksson B, Sundin A, Lundqvist H \& Lubberink M 2013 Individualized dosimetry of kidney and bone marrow in patients undergoing 177Lu-DOTA-octreotate treatment. Journal of Nuclear Medicine 54 33-41. (doi:10.2967/jnumed.112.107524)

Sawka AM, Thephamongkhol K, Brouwers M, Thabane L, Browman G \& Gerstein HC 2004 Clinical review 170: a systematic review and metaanalysis of the effectiveness of radioactive iodine remnant ablation for well-differentiated thyroid cancer. Journal of Clinical Endocrinology and Metabolism 89 3668-3676. (doi:10.1210/jc.2003-031167)

Schroeder T, Kuendgen A, Kayser S, Kroger N, Braulke F, Platzbecker U, Klarner V, Zohren F, Haase D, Stadler M, et al. 2012a Therapy-related myeloid neoplasms following treatment with radioiodine. Haematologica 97 206-212. (doi:10.3324/haematol.2011.049114)

Schroeder T, Kuendgen A, Kayser S, Kroger N, Braulke F, Platzbecker U, Klarner V, Zohren F, Haase D, Stadler M, et al. 2012b Therapy-related myeloid neoplasms following treatment with radioiodine. Haematologica 97 206-212. (doi:10.3324/haematol.2011.049114)

Strosberg J, Wolin EM, Chasen B, Kulke M, Bushnell DL Jr, Caplin M, Baum RP, Mittra E, Hobday T, Hendifar A, et al. 2015 177-Lu-Dotatate significantly improves progression-free survival in patients with midgut neuroendocrine tumours: results of the phase III NETTER-1 trial. European Journal of Cancer 51 S710. (doi:10.1016/ s0959-8049(16)31929-3)

Sun LM, Lin CL, Lin MC, Liang JA \& Kao CH 2015 Radiotherapy- and chemotherapy-induced myelodysplasia syndrome: a nationwide population-based nested case-control study. Medicine 94 e737. (doi:10.1097/md.0000000000000737)

van Essen M, Krenning EP, Kam BL, de Herder WW, van Aken MO \& Kwekkeboom DJ 2008 Report on short-term side effects of treatments with $177 \mathrm{Lu}$-octreotate in combination with capecitabine in seven patients with gastroenteropancreatic neuroendocrine tumours. European Journal of Nuclear Medicine and Molecular Imaging 35 743-748. (doi:10.1007/s00259-007-0688-7)

Vardiman JW, Thiele J, Arber DA, Brunning RD, Borowitz MJ, Porwit A, Harris NL, Le Beau MM, Hellstrom-Lindberg E, Tefferi A, et al. 2009 The 2008 revision of the World Health Organization (WHO) classification of myeloid neoplasms and acute leukemia: rationale and important changes. Blood 114 937-951. (doi:10.1182/blood-2009-03-209262)

Zhang L \& Wang SA 2014 A focused review of hematopoietic neoplasms occurring in the therapy-related setting. International Journal of Clinical and Experimental Pathology 7 3512-3523.

Received in final form 20 June 2016

Accepted 27 June 2016

Accepted Preprint published online 27 June 2016
C 2016 Society for Endocrinology Printed in Great Britain
Published by Bioscientifica Ltd. 